\title{
CONFERENCIAS SOBRE ARTE MODERNO MEXICANO EN LA UNIVERSIDAD DE TEXAS
}

Por invitación especial que hizo a uno de nuestros investigadores, el señor Justino Fernández, el Institute of Latin-American Studies, de la Universidad de Texas, a iniciativa del profesor de arte de aquella institución, señor Gibson Danes, dicho investigador se trasiadó a la población de Austin, Texas, y dió un cursillo de tres conferencias, según el siguiente programa :

\section{"Verdad y Carácter del Arte Moderno Mexicano"}

I. El arte vital de José Clemente. Orozco.

II. E1 arfe idealista de Diego Rivera.

III. Corrientes de la pintura mexicana contemporánea.

En esta última conferencia se habló de todos los artistas importantes contemporáneos:

Las conferencias fueron dictadas en inglés; se usaron diapositivas a color del archivo que ha formado el Departamento de Arte de aquella Universidad y tuvieron lugar en el Auditorio de la Facultad de Geología, los días 11,12 y 13 de noviembre próximo pasado, ante numeroso público.

El Institute of Latin American Studies, presidido por el doctor Charles W. Hackett, ofreció un almuerzo al señor Fernández, con asistencia del Presidente de la Universidad, señor Homer P. Rainey; y de los profesores de todas las facultades. El señor Rainey expresó en breves y cordiales palabras que el agasajo era en honor de la Universidad Nacional Autónoma de México, representada por nuestro investigador, quien respondió agradeciendo, en nombre de la Universidad, la distinción recibida. Tanto los diarios de Austin, como los de Dallas, dieron noticias pormenorizadas de cada una de las conferencias.

Este Instituto hace patente su agradecimiento a las autoridades de la Universidad de Texas, al Institute of Latin-American Studies, a los miembros del Departamento de Arte y demás profesores, por las atenciones dispensadas al señor Justino Fernández, durante su estancia en Austin. 